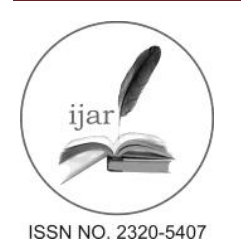

Journal homepage:http://www.journalijar.com
Journal DOI:10.21474/IJAR01

RESEARCH ARTICLE
INTERNATIONAL JOURNAL

OF ADVANCED RESEARCH

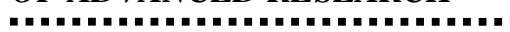

\title{
SERUM CHEMERIN AS A PREDICTOR OF CORONARY ARTERY DISEASES IN TYPE 2 DIABETES
}

Hala Abdel-Hameed Abdel-Azeez ${ }^{1}$, Manar Mostafa Al-Zaki ${ }^{2}$, Maher Borai MohammadBorai ${ }^{1}$.

1. Clinical PathologyDepartment, Faculty of Medicine, Zagazig University, Egypt.

2. CardiologyDepartment,Faculty of Medicine, Zagazig University, Egypt.

\section{Manuscript Info Abstract \\ Manuscript History:}

Received: 11 April 2016

Final Accepted: 13 May 2016

Published Online: June 2016

Key words:

type 2 diabetes, coronary artery

diseases, serum chemerin

*Corresponding Author

Manar Mostafa Al-Zaki.
Chemerin is anadipokine that has attracted considerable interest due to an increasing body of evidence supporting its roles in adipogenesis, energy metabolism, and inflammation. Our objective was to determine the level of serum chemerin in type 2 diabetic (T2DM) patients and to evaluate its role as a predictor of coronary artery diseases (CAD)in these patients. This case control study was carried out on 30 T2DM patients without CAD, 30 T2DMpatients with CAD and 30 apparently healthy, age and sex matched subjects. CAD was diagnosed as presence of one or more coronary arteries with significant stenosis $(\geq 50 \%)$ and its severity was evaluated by Gensiniscore.All studied individuals were subjected to determination of fasting glucose, glycated hemoglobin, lipid profile, high sensitive c reactive protein (hsCRP) and serumchemerin.Our result revealed that serum chemerin was significantly increased in diabetic patients compared to controls and in diabetic patients with CAD compared to those without CAD. It was significantly correlated with hsCRP and Gensini score in CAD patients.Increasing chemerin was an independent predictor of CAD in T2DM.Receiver operating characteristic curve analysis of chemerin revealed anarea under curve of 0.949 . At cut off value of $>375 \mathrm{ng} / \mathrm{L}$, chemerin had $96.7 \%$ sensitivity and $86.6 \%$ specificity in prediction of CAD in T2DM patients. In conclusion, serum chemerin was increased in type 2 diabetic patients and associated with CAD in these patients. Itwas correlated with disease severity and can be used in prediction of CAD in type 2 diabetic patients.

Copy Right, IJAR, 2016. All rights reserved.

\section{INTRODUCTION}

Diabetes, because of its vascular complications, is associated with a high risk of morbidity and mortality. The high incidence of cardiovascular complications, including coronary artery, peripheral artery and cerebrovascular diseases has been associated to the hyperglycemia-induced oxidative stress, endothelial dysfunction and lack of endothelial regeneration. This results in abnormal vascular remodeling and impaired neovascularization(American Diabetes Association 2007).

Chemerin is a recently identified adipokine that has attracted considerable interest due to an increasing body of evidence supporting roles for this adipokine in adipogenesis, energy metabolism, and inflammation. In particular, chemerin has been hypothesized as a possible link between obesity and the development of type 2 diabetes mellitus (T2DM) (Kaur et al., 2010).Chemerin is also an identified chemoattractant protein that induces leukocyte migration; in addition, its receptor is expressed by tissue macrophages. These observations suggest that chemerin functions in the development of inflammatory diseases, including atherosclerosis(Ernst et al., 2011). 
The aim of the present study was to determine the level of serum chemerin in type 2 diabetic patients and to evaluate its role as a predictor of coronary artery diseases $(\mathrm{CAD})$ in these patients.

\section{SUBJECTS\&METHODS}

\section{Subjects:-}

This case control study was carried out on 90 subjects classified into; 30type 2 diabetic patients without CAD, 30type 2 diabetic patients with CAD and 30apparently healthy, age and sex matched subjects as control group. Type 2 diabetes is defined according to American Diabetes Association (2016). CAD was diagnosed as presence of one or more coronary arteries with significant stenosis $(\geq 50 \%)$.

Coronary angiography is performed under local anesthesia using Seldinger technique with right femoral approach (Seldinger, 1953 ). Gensiniscore was calculated from the number of stenotic coronary artery segments and the degree of lumen stenosis (Gensini, 1983).

Patients who had any of the following conditions were excluded from our study: ejection fraction less than 50\% calculated by Simpsons method,chronic viral hepatitis, liver cell failure, renal dysfunction, malignancy, myocarditis, pericarditis, active inflammatory disease, acute infections, severe medical illness, andnutritional derangement.

\section{Laboratory investigations:-}

Fasting glucose,lipid profile,HbA1c and hsCRPwere analyzed on Cobas6000 analyzer (Roche Diagnostics).Serum chemerin levelsweredetermined using a commercially available enzyme- linked immunosorbent assay (ELISA) kit (Glory Science Co, USA), according to manufacturer's protocol. The detection limit is 20-1200ng/L.

\section{Statistical analysis:-}

Sample size was calculated with 95\%confidence interval and $80 \%$ power (Open Epi). All data were analyzed using SPSS 20.0 for windows (SPSS Inc., Chicago, IL, USA) and MedCalc 13 for windows (MedCalc Software bvba, Ostend, Belgium).Continuous variables were checked for normality by using Shapiro-Wilk test. Continuous variables were expressed as the mean \pm standard deviation (SD)or median (range), and the categorical variables were expressed as a number(percentage). One-Way ANOVA was used to compare groups of normally distributed data while Kruskal-Wallis $\mathrm{H}$ test was used for non-normally distributed data. Percent of categorical variables were compared using the Chi-square test. Spearman's rank correlation analysis was done between chemerin and selected study parameters. Univariate regression analysis was done to assess role of chemerin as an independent predictors for CAD in type 2 diabetic patients. Receiver operating characteristic (ROC) curve analysis was used to identify optimal cut-off values of chemerin and hsCRP with maximum sensitivity and specificity for prediction of CAD. Area Under Curve (AUROC) was also calculated, All tests were two tailed. $\mathrm{P}<0.05$ was considered statistically significant, $\mathrm{p}<0.01$ was considered highly statistically significant, and $\mathrm{p}>0.05$ was considered nonstatistically significant. 


\section{RESULTS}

Table 1: Demographic and clinical characteristics of the studied groups.

\begin{tabular}{|c|c|c|c|c|}
\hline $\begin{array}{l}\text { Demographic and } \\
\text { Clinical data }\end{array}$ & $\begin{array}{c}\text { Healthy controls } \\
(\mathrm{N}=30)\end{array}$ & $\begin{array}{l}\text { Diabetics without } \\
\text { CAD }(\mathrm{N}=30)\end{array}$ & $\begin{array}{c}\text { Diabetics with CAD } \\
(\mathrm{N}=30)\end{array}$ & $\mathbf{p}$ \\
\hline Age (years) ${ }^{\#}$ & $\begin{array}{c}55.8 \pm 6.57 \\
(42-66)\end{array}$ & $\begin{array}{c}56.1 \pm 6.35 \\
(43-65)\end{array}$ & $\begin{array}{c}57.7 \pm 6.40 \\
(45-69)\end{array}$ & 0.457 \\
\hline $\begin{array}{l}\text { Sex } \\
\text { Male } \\
\text { Female }\end{array}$ & $\begin{array}{l}14(46.7) \\
16(53.3)\end{array}$ & $\begin{array}{l}13(43.3) \\
17(56.7)\end{array}$ & $\begin{array}{l}20(66.7) \\
10(33.3)\end{array}$ & 0.147 \\
\hline $\begin{array}{l}\text { Smoking } \\
\text { Non-smoker } \\
\text { Smoker }\end{array}$ & $\begin{array}{l}22(73.3) \\
8(26.7)\end{array}$ & $\begin{array}{l}20(66.7) \\
10(33.3)\end{array}$ & $\begin{array}{l}16(53.3) \\
14(46.7)\end{array}$ & 0.257 \\
\hline $\begin{array}{l}\text { Physical activity } \\
\text { No } \\
\text { Yes }\end{array}$ & $\begin{array}{l}21(70) \\
9(30)\end{array}$ & $\begin{array}{l}23(76.7) \\
7(23.3)\end{array}$ & $\begin{array}{r}27(90) \\
3(10)\end{array}$ & 0.154 \\
\hline SBP $(\mathrm{mmHg})^{\$}$ & $\begin{array}{c}120 \\
(110-140)\end{array}$ & $\begin{array}{c}120 \\
(110-140)\end{array}$ & $\begin{array}{c}140^{*} \\
(120-140)\end{array}$ & $<0.001$ \\
\hline DBP (mmHg) ${ }^{\$}$ & $\begin{array}{c}80 \\
(70-90)\end{array}$ & $\begin{array}{c}80 \\
(70-90)\end{array}$ & $\begin{array}{c}90 * \\
(80-90)\end{array}$ & $<0.001$ \\
\hline BMI $\left(\mathrm{Kg} / \mathrm{m}^{2}\right)^{\$}$ & $\begin{array}{c}27.6 \\
(21.6-39.9)\end{array}$ & $\begin{array}{c}27.85 \\
(23.4-35.1)\end{array}$ & $\begin{array}{c}27.45 \\
(22.3-39)\end{array}$ & 0.994 \\
\hline
\end{tabular}

Data are presented as median ${ }^{\$}$, mean \pm standard deviation" (range) or number(\%).

$\mathrm{N}$ : Number of subjects.

*Significantly different from other groups.

Table 2:Laboratory findingsin the studied groups.

\begin{tabular}{|c|c|c|c|c|}
\hline \multirow[t]{2}{*}{ Laboratory findings } & $\begin{array}{l}\text { Healthy } \\
\text { controls }\end{array}$ & $\begin{array}{c}\text { Diabetics without } \\
\text { CAD }\end{array}$ & Diabetics with CAD & \multirow[t]{2}{*}{$\mathbf{p}$} \\
\hline & $(\mathrm{N}=30)$ & $(\mathrm{N}=30)$ & $(\mathrm{N}=30)$ & \\
\hline Fasting Glucose (mg/dl) & $\begin{array}{c}79.5 * \\
(73-94)\end{array}$ & $\begin{array}{c}132 \\
(108-343)\end{array}$ & $\begin{array}{c}134.5 \\
(106-334)\end{array}$ & $<0.001$ \\
\hline HbA1c (\%) & $\begin{array}{c}3.95 * \\
(2.3-5)\end{array}$ & $\begin{array}{c}4.3 \\
(2.7-6.1)\end{array}$ & $\begin{array}{c}4.65 \\
(2.8-6.2)\end{array}$ & 0.009 \\
\hline Total cholesterol $(\mathrm{mg} / \mathrm{dl})$ & $\begin{array}{c}119 \\
(79-205)\end{array}$ & $\begin{array}{c}118 \\
(78-231)\end{array}$ & $\begin{array}{c}200.5^{*} \\
(111-306)\end{array}$ & $<0.001$ \\
\hline Triglycerides (mg/dl) & $\begin{array}{c}85.5 \\
(33-183)\end{array}$ & $\begin{array}{c}78 \\
(51-199)\end{array}$ & $\begin{array}{c}174 * \\
(77-443)\end{array}$ & $<0.001$ \\
\hline HDL-C (mg/dl) & $\begin{array}{c}41 \\
(24-61)\end{array}$ & $\begin{array}{c}46.5 \\
(28-55)\end{array}$ & $\begin{array}{l}34.5 * \\
(6-81)\end{array}$ & $<0.001$ \\
\hline LDL-C (mg/dl) & $\begin{array}{c}55.5 \\
(21-130)\end{array}$ & $\begin{array}{c}58.5 \\
(20-151)\end{array}$ & $\begin{array}{c}125^{*} \\
(53-228)\end{array}$ & $<0.001$ \\
\hline hsCRP (mg/L) & $\begin{array}{c}1.4 \\
(0.2-3.8) \\
\end{array}$ & $\begin{array}{c}2.05 \\
(0.8-5.2) \\
\end{array}$ & $\begin{array}{c}8.3^{*} \\
(3.5-56.4) \\
\end{array}$ & $<0.001$ \\
\hline Chemerin (ng/L) & $\begin{array}{c}190 \\
(130-240)\end{array}$ & $\begin{array}{c}330 * \\
(230-690)\end{array}$ & $\begin{array}{c}625^{*} \\
(380-985)\end{array}$ & $<0.001$ \\
\hline
\end{tabular}

Data are presented as median (range).

$\mathrm{N}$ : Number of subjects.

*Significantly different from other groups. 


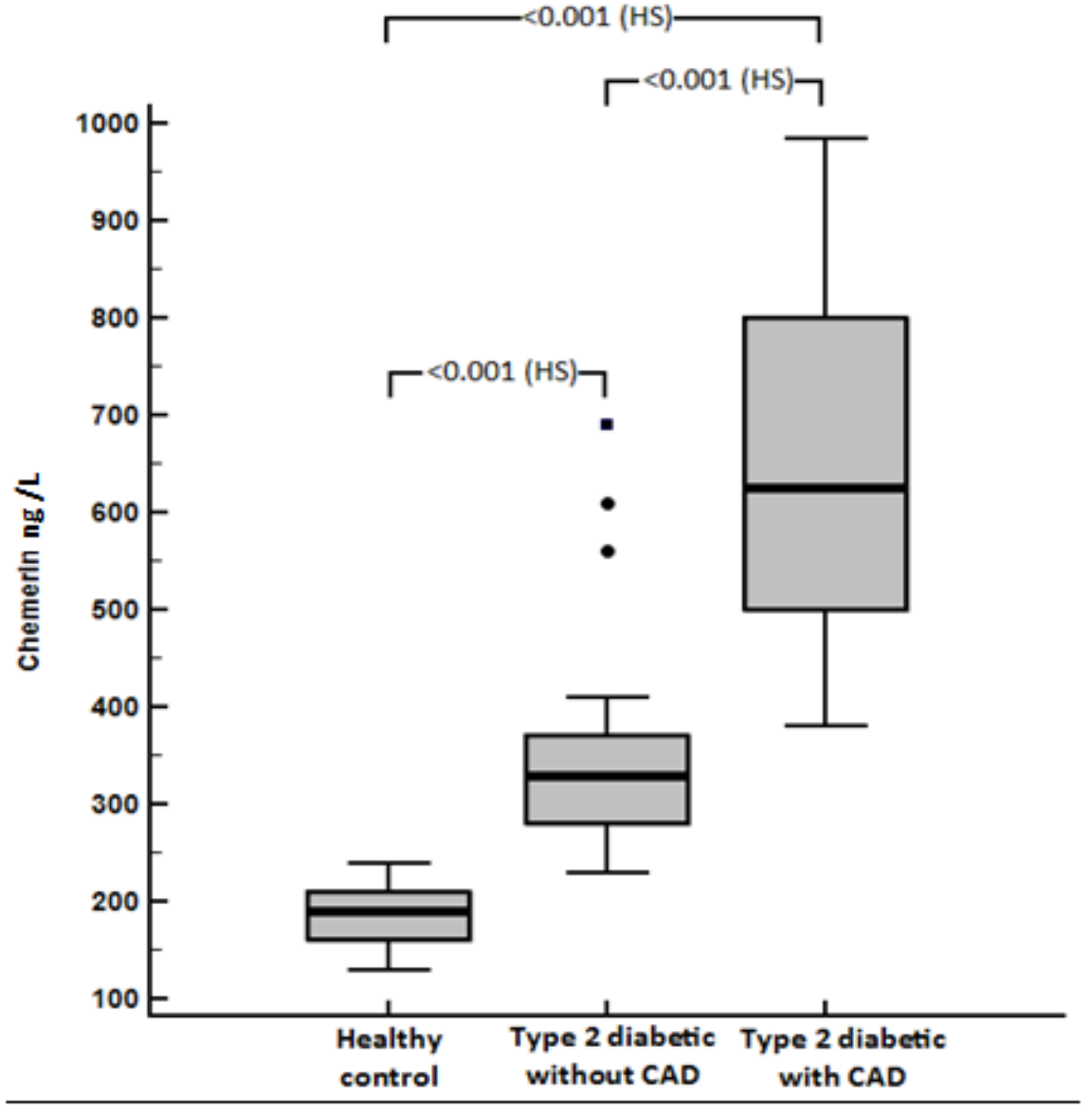

Figure 1:Box-plot for serumchemerinin the studied groups.HS: highly significant.

Table 3:Correlation between chemerin(ng/L)and some studied parameters in type 2 diabetic patients.

\begin{tabular}{|c|c|c|c|c|}
\hline \multirow[t]{2}{*}{ Parameter } & \multicolumn{2}{|c|}{ Diabetics without CAD } & \multicolumn{2}{|c|}{ Diabetics with CAD } \\
\hline & $\mathbf{r}$ & $\mathbf{p}$ & $\mathbf{r}$ & $\mathbf{P}$ \\
\hline Age (years) & -0.181 & 0.339 & +0.092 & 0.628 \\
\hline SBP (mmHg) & +0.094 & 0.623 & -0.010 & 0.957 \\
\hline DBP (mmHg) & +0.062 & 0.746 & +0.111 & 0.560 \\
\hline BMI (Kg/m2) & +0.558 & $0.001 *$ & +0.183 & 0.332 \\
\hline Fasting glucose (mg/dl) & +0.620 & $<0.001 *$ & +0.125 & 0.509 \\
\hline HbA1c $(\%)$ & +0.101 & 0.596 & -0.025 & 0.897 \\
\hline Total cholesterol (mg/dl) & +0.076 & 0.691 & -0.007 & 0.970 \\
\hline Triglycerides (mg/dl) & +0.153 & 0.421 & -0.083 & 0.662 \\
\hline HDL-C (mg/dl) & -0.181 & 0.337 & +0.051 & 0.787 \\
\hline LDL-C (mg/dl) & +0.125 & 0.509 & -0.050 & 0.793 \\
\hline hsCRP (mg/L) & +0.718 & $<0.001 *$ & +0.862 & $<0.001^{*}$ \\
\hline Gensini score & \multicolumn{2}{|c|}{ NA } & +0.687 & $<0.001 *$ \\
\hline Number of affected vessels & \multicolumn{2}{|c|}{ NA } & +0.126 & 0.506 \\
\hline
\end{tabular}

*Significant.

NA: not applicable 
Table 4:hsCRP and chemerinas predictors for CAD in type 2 diabetic patients.

\begin{tabular}{|l|c|c|c|c|c|c|}
\hline Parameter & SN \% & SP \% & PPV \% & NPV \% & Accuracy & $\begin{array}{c}\text { AUROC (95\% } \\
\text { CI) }\end{array}$ \\
\hline $\begin{array}{l}\text { hsCRP } \\
>3.0 \mathrm{mg} / \mathrm{L}\end{array}$ & $90 \%$ & $90 \%$ & $90 \%$ & $90 \%$ & $90 \%$ & 0.946 \\
$\begin{array}{l}\text { Chemerin } \\
>375 \mathrm{ng} / \mathrm{L}\end{array}$ & $96.7 \%$ & $86.6 \%$ & $88.2 \%$ & $96.3 \%$ & $91.7 \%$ & $\begin{array}{c}0.945-0.988) \\
(0.860-0.989)\end{array}$ \\
\hline Chemerin and hsCRP & $100 \%$ & $90 \%$ & $90.9 \%$ & $100 \%$ & $95 \%$ & $\begin{array}{c}0.988 \\
(0.858-0.989)\end{array}$ \\
\hline
\end{tabular}

SN: Sensitivity.

SP: Specificity.

PPV: Positive Predictive Value.

NPV: Negative Predictive Value.

AUROC: Area Under Receiver Operating Characteristic curve.

95\%CI: 95\% Confidence Interval.

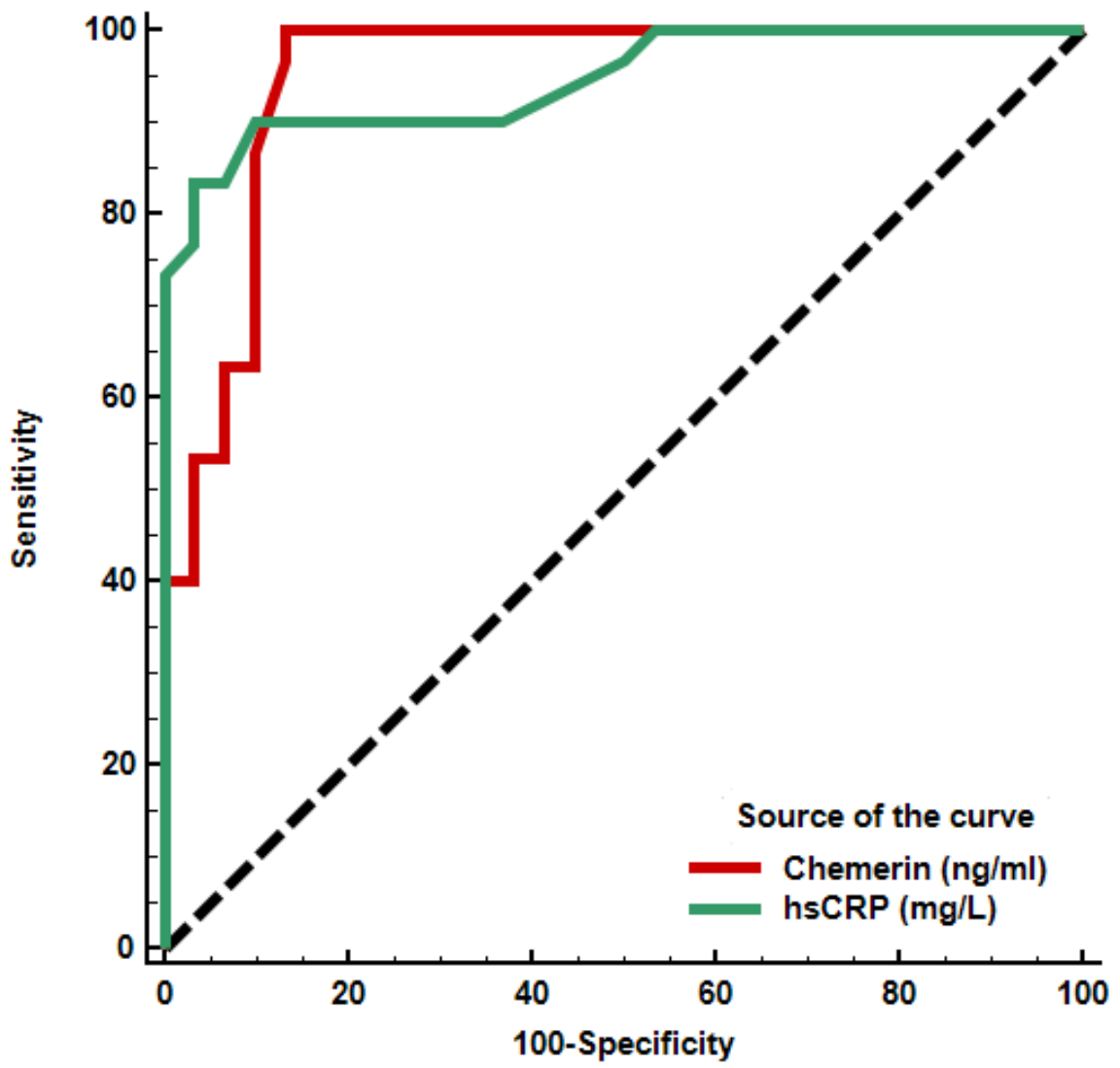

Figure 2: Receiver operating characteristic (ROC) curve of chemerin and hsCRPas predictors for CAD in type 2 diabetic patients.

Table 1 shows demographic and clinical characteristics of the studied groups. In diabetic patients with CAD, the mean \pm SD (range) of Gensini score was 33.5 \pm 32.14 (5-96). Laboratory findings are presented in table 2. Serum chemerin was significantly increased in diabetic patients compared to controls and in diabetic patients with CAD compared to those without CAD (figure 1). Serum chemerin was significantly correlated with hsCRPin diabetic groups and with Gensini score in CAD patients (table 3).

Logistic regression analysis revealed that increasing chemerinlevel wasan independent predictor of CAD in type 2 diabetic patients ( $\beta$ regression Coefficient \pm standard error is $0.014 \pm 0.004, \mathrm{p}<0.001$ ). 
ROC curve analysis of hsCRPrevealed an AUROC of 0.946.At cut off value of > 3.0 mg/L, 27 out of $30 \mathrm{CAD}$ patients were correctly diagnosed. ROC curve analysis of serum chemerinrevealed an AUROC of 0.949.At cut off value of $>375 \mathrm{ng} / \mathrm{L}, 29$ out of $30 \mathrm{CAD}$ patients were correctly diagnosed. When using chemerin and hsCRP in combination, all CAD were correctly diagnosed (100\% sensitivity) (table 4 , figure 2 ).

\section{DISCUSSION}

Early prediction of CADin diabetic patients is important for early management.Serum biomarkers are important tools for prediction, diagnosis, risk stratification and therapeutic decision- making for patients with cardiovascular disease (Corson et al., 2009). The present study revealed that chemerin level was significantly higher in type 2 diabetic patients compared to control group andin diabetic patients with CAD compared to those without CAD (Ali and Al-hadidi, 2013). Our results confirm previous researches that reported increased serumchemerin in type 2 diabetic patients with atherosclerosis (Elsaid et al., 2013). In contrast,El-Mesallamy et al.(2011)didn't reveal significant differences in serum chemerinbetween type 2 diabetic patients with and without CAD.

Higher chemerin release is associated with insulin resistance in skeletal muscles by decreasing the rate of auto phosphorylation and subsequent downstream intracellular signaling cascades of insulin receptor tyrosine kinase activity in peripheral tissues. Chemerin also inhibits glycogen synthase kinase phosphorylation, an enzyme necessary for glycogen synthesis and storage, and thus inhibits glucose uptake. In addition, chemerin activates extracellular signal-regulated kinase (ERK). Inhibition of ERK prevents chemerin induced insulin resistance, pointing to participation of this pathway in chemerin action (Sell et al.,2009).

Logistic regression analysis in this study revealed that increased chemerin is an independent predictor of CAD in type 2 diabetic patients. Similar findings were previously reported in metabolic syndrome patients (Dong et al., 2011 and Askan et al., 2014)and in CAD patients(Xiaotao et al., 2012). We also confirmed the previous results that reported a significant positive correlation between serum chemrin and disease severity evaluated by Gensini score(Yan et al., 2012 and Bozaoglu et al., 2010).

Chemerin activates extracellular signal-regulated kinase (p38 MAPK and ERK1/2 action), stimulates blood vessels migration, invasion, and formation, and leads to angiogenesis(Bozaoglu et al.,2010). Chemerin also promotes migration of inflammatory cells, including monocytes and macrophages, into atherosclerotic plaques by chemotaxis. The activation and penetration of monocytes and macrophages in atherosclerotic plaques are important factors resulting in plaque instability, which induces the rupture of plaque and eventual thrombus formation(Zhao et al.,2015). Moreover, chemerin is expressed in both the foam cellsand vascular smooth muscle cells of these atheroscleroticlesions and correlates with overall disease burden. Not onlydoes this support a role for chemerin in the pathogenesisof atherosclerosis, but itlends support to the importance of localized autocrine/paracrine functions of chemerin within the heart (Ernst et al., 2010).

Our study revealed significant positive correlation between chemerin level and hsCRP in type 2 diabetic patientswith and without CAD. Similar findings were reportedpreviously in metabolic syndrome(Abdelhaleem et al., 2012 and Lehrke et al., 2009). Endothelial cells express both chemerin and its receptor, CMKLR1, and it is regulated by tumor necrosis factor- $\alpha$ (TNF- $\alpha$ ), interleukin-6 (IL-6), interleukin-1 $\beta$ (IL-1 $\beta$ ), and other proinflammatory cytokines. After being stimulated by inflammatory cytokines, endothelia cells were damaged, triggering macrophages that remain in artery walls by a variety of adhesion and migration activities. Macrophages move lipids into foam cells, promoting the development of atherosclerosis (Kaur et al., 2010).

In the present study, ROC curve analysis of chemerin revealed an AUROC of 0.949 which was comparable with that of hsCRP (0.946). At cut off value of $>375 \mathrm{ng} / \mathrm{L}$, serum chemerinpredicted CAD in type 2 diabetic patients with $96.7 \%$ sensitivity and86.6\% specificity. When usingchemerinand hsCRP in combination, all CAD were correctly diagnosed(100\% sensitivity).

In conclusion serum chemerin was increased in type 2 diabetic patients and associated with CADin these patients. It was correlated with disease severity and can be used in prediction of CAD in type 2 diabetic patient.Further studies on large sample size to confirm these resultsare recommended. 


\section{REFERENCES}

1. Abdelhaleem, A.A. and Al-salamony, A.M. (2012).Serum chemerin and adiponectin levels in metabolic syndrome patients with or without coronary arterydiseases. Journal of American Science; 8(9): 387-394.

2. Aksan, G., İnci, S., Nar, G., Soylu, K., Gedikli, Ö., Yüksel, S., Özdemir, M., Nar, R., Meriç, M., Şahin, M. (2014).Association of serum chemerin levels with the severity of coronary artery disease in patients with metabolic syndrome. Int J Clin Exp Med; 7(12)5461-5468.

3. Ali, T.M. and Al-Hadidi, K. (2013).Chemerin is associated with markers of inflammation and predictors of atherosclerosis in Saudi subjects with metabolic syndrome and type 2 diabetes mellitus. Beni-suef University Journal of Basic and Applied Sciences; 2: 86-95.

4. American Diabetes Association (2007).Standards of medical care in diabetes. Diabetes Care; 30(suppl 1): S4S41.

5. American Diabetes Association(2016). Classification and diagnosis of diabetesmellitus. Diabetes Care; 39(1): S13-S22.

6. Bozaoglu, K., Curran, J.E., Stocker, C.J., Zaibi, M.S., Segal, D., Konstantopoulos, N., Morrison, S., Carless, M., Dyer, T.D., Cole, S.A., Goring, H.H., Moses, E.K., Walder, K., Cawthorne, M.A., Blangero, J., Jowett, J.B. (2010).Chemerin, a novel adipokine in the regulation of angiogenesis.J ClinEndocrinolMetab;95(5):2476-2485.

7. Corson, M.A.(2009).Emerging inflammatory markers for assessing coronary heart disease risk.CurrCardiolRep;11:452-459.

8. Dong, B., Ji, W., Zhang, Y. (2011).Elevated serum chemerin levels are associated with the presence of coronary artery disease in patients with metabolic syndrome. Intern Med; 50: 1093-1097.

9. El-Mesallamy, H.O., El-Derany, M.O., Hamdy, N.M. (2011). Serum omentin-1 and chemerin levels are interrelated in patients with Type 2 diabetes mellitus with or without ischaemic heart disease. Diabetic Medicine; 28(10):1194-1200.

10. Elsaid, N.H., Fawzy, M.W., Mohammed, N.A., Ahmed, A.Z. (2013).Role of serum chemerin level in atherosclerosis in Egyptian patients with type 2 diabetes mellitus. Journal of applied Sciences Research; 9(1):778-785.

11. Ernst, M.C. and Sinal, C.J. (2010).Chemerin: at the crossroads of inflammation and obesity. Trends in Endocrinology \& Metabolism; 21 (11): 660-667.

12. Ernst, M.C., Haidl, I.D., Zúñiga, L.A., Dranse, H.J., Rourke, J.L., Zabel, B.A., Butcher, E.C., Sinal, C.J. (2011). Disruption of the chemokine-like receptor-1 (CMKLR1) gene is associated with reduced adiposity and glucose intolerance. Endocrinology; 153(2):672-682.

13. Gensini, G.G. (1983).A more meaningful scoring system for determining the severity of coronary heart disease. Am J Cardiol; 5:606.

14. Kaur, J., Adya, R., Tan, B.K., Chen, J. and Randeva, H.S. (2010).Identification of chemerin receptor (ChemR23) in human endothelial cells: Chemerin-induced endothelial angiogenesis.BiochemBiophys Res Comnmn; 391: 1762-1768.

15. Lehrke, M., Becker, A., Greif, M. (2009).Chemerin is associated with markers of inflammation and components of the metabolic syndrome but does not predict coronary atherosclerosis. Eur J Endocrinol; 161: 339-344.

16. Seldinger, S.I. (1953).Catheter replacement of the needle in percutaneous arteriography. Acta Radio; 139: 368376.

17. Sell, H.,Laurencikiene, J.,Taube, A., Eckardt, K., Cramer, A., Horrighs, A., Arner, P., Eckel, J. (2009).Chemerin is a novel adipocyte-derived factor inducing insulin resistance in primary human skeletal muscle cells. Diabetes; 58(12): 2731-2740.

18. Xiaotao, L., Xiaoxia, Z., Yue, X., Liye. W. (2012).Serum chemerin levels are associated with the presence and extent of coronary artery disease. Coronary Artery Disease; 23: 412-416.

19. Yan, Q., Zhang, Y., Hong, J., Gu, W., Dai, M., Shi, J., Zhai, Y., Wang, W., Li. X., Ning, G. (2012).The association of serum chemerin level with risk of coronary artery disease in Chinese adults.Endocrine; 41(2): 281-288.

20. Zhao, D., Bi, G., Feng, J., Huang, R., Chen, X. (2015).Association of serum chemerin levels with acute ischemic stroke and carotid artery atherosclerosis in a Chinese population. Medical Science Monitor: International Medical Journal of Experimental and Clinical Research; 21, 3121-3128. 